\title{
Our self-driving future will be shaped by policies of today
}

\author{
Autonomous vehicles are not a panacea for the issues that currently plague transportation systems. Smart policies \\ - which are flexible enough to deal with emerging technologies - are required to help cities and states realize the \\ benefits of these vehicles.
}

\section{Matthew D. Dean and Kara Kockelman}

\begin{abstract}
$\mathrm{T}$ here are numerous predictions about the potential benefits of autonomous vehicles $^{1}$, from safer roads with fewer crashes to reduced emissions and lower congestion $^{2}$. But if autonomous vehicles are to transform passenger and freight mobility, fundamental policy changes need to occur; otherwise, cities are likely to see similar challenges that affect transportation systems today.

The true costs of driving need to reflect environmental and societal costs. If not, car-centred systems will continue with autonomous vehicles. If there are continued subsidies in the form of minimum parking requirements, added lanes and suburban development patterns - which create an environment that requires a car - then the policy question of "how do we get people out of their cars?" remains unanswered. Designing cities to give people efficient, reliable, safe and affordable alternatives, such as transit, cycling and walking, is as critical to the future of transportation as the use of new technologies. Policy solutions that shift the responsibility of driving costs could address these existing issues and ensure maturing technologies avoid 'potholes' in the future.
\end{abstract}

\section{Two self-driving futures}

Early adopters of autonomous vehicle technology are likely to be fleets offering passenger service, though freight won't be far behind. Shared autonomous vehicle services have already begun operating in limited use cases around the world ${ }^{3}$. After securing regulatory approval, such services will provide door-to-door private passenger service and offer reduced fares for passengers willing to share the ride with strangers. The services may complement traditional public transit services, such as rail, through first-mile/last-mile transfers or partially replace less-used local buses.

Over time, households may choose to buy a personal autonomous vehicle or rely on a mix of competitive mobility providers, from line-haul transit to on-demand shared autonomous electric vehicles ${ }^{4-6}$. In the absence of policy changes to address transportation revenue shortfalls, on-road emissions and congestion, the transition to a world with autonomous vehicle technology may lead to one of two self-driving futures: car-dependent sprawl or shared multi-modal compact cities.

In the business-as-usual sprawl scenario, suburban and exurban towns continue to attract low-density, car-dependent development through loose land-use policies. Households buy an autonomous vehicle to make better use of their in-vehicle travel time (reading or working, for example) and to reduce driving stress or fatigue ${ }^{7}$. A combination of sprawl, better use of travel time and increased demand from previously underserved populations (such as seniors, people with disabilities and those without a driver's license) lead to increased per-capita vehicle-miles travelled ${ }^{8}$. Lane expansions - the time-tested action of alleviating congestion - lead to the same, if not more, congestion through induced demand ${ }^{9}$. Personal autonomous vehicles substantially change long-distance travel behaviour by substituting for air travel ${ }^{10}$. Electric personal autonomous vehicles are adopted due to lower costs and electric powertrain benefits for the onboard computer systems. But longer trips, more people able to travel (without having to drive), more computing power (required to run an autonomous vehicle), empty-vehicle driving (if permitted by policymakers and enforcement agencies) and mode shifts (away from biking and electric trains, for example) can more than offset energy consumption improvements ${ }^{11}$. In this scenario, cities and states trade gains in property tax revenues for long-term infrastructure maintenance and congestion costs.

In the optimistic scenario, cities encourage compact, transit-oriented developments with safe routes for non-motorized travel for all levels of comfort $^{12}$. Households living near dense urban centres have multiple travel modes available for most destinations and give up car ownership to save money. Investments in separated pedestrian and bicycle infrastructure, electric bikeshare programmes and converting temporary COVID-19 street reallocation pilots to permanent fixtures of urban life increases daily active transportation and improves physical well-being. A mix of autonomous vehicle services complements light-rail transit and commuter rail ${ }^{13}$. For example, demand-response autonomous minibuses lower wait times and are sized to meet temporal changes in demand ${ }^{14}$. Shared autonomous electric vehicles offer private door-to-door rides and pooled rides for travellers willing to take a slight detour for a reduced fare. Right-sizing vehicles to match occupancy levels and sharing rides saves money overall, takes solo cars off the road and reduces the energy demands of transportation. Fewer privately owned vehicles lower the demand for urban parking, which may increase opportunities for green redevelopment, reduce the urban heat island effect and stormwater runoff, and create more cohesive communities. Abundant travel choices (Fig. 1) increase the frequency of trips, but sharing all-electric vehicles and rides, paired with more active transport modes (such as cycling and walking), may counteract the societal costs that come with a rise in travel.

\section{Paying your fair share}

Even with the uncertainty that surrounds autonomous vehicles, many of the predictions on its potential benefits - in terms of travel times and traffic volumes are too good to be true. And the myth of autonomous vehicles reducing congestion and travel times is far from new. Relying on technology in the future to solve today's challenges is not realistic and ignores how policies today can shape the development of autonomous vehicles tomorrow. Cities must first acknowledge the current problems and 


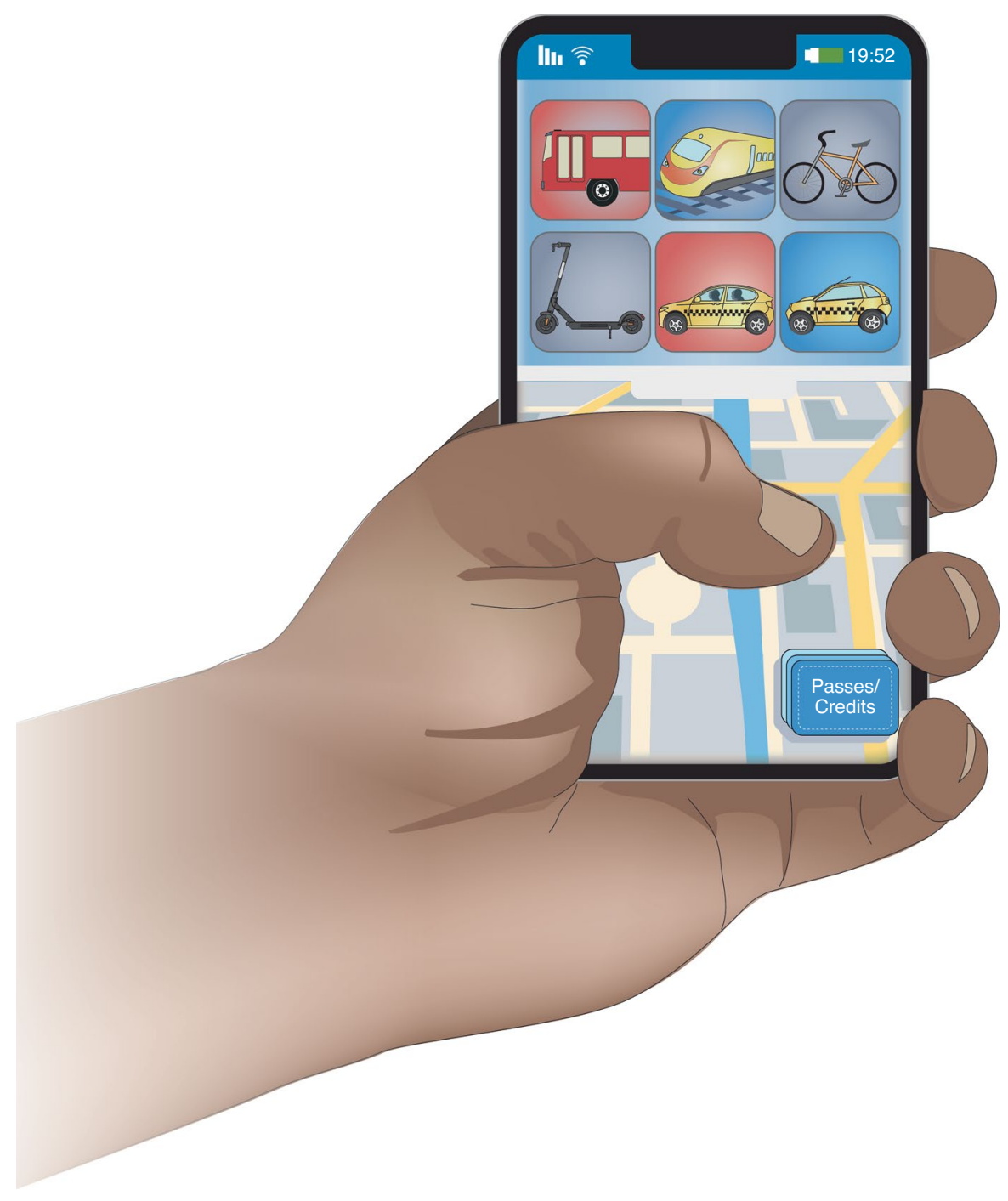

Fig. 1 | Future travel options. Much like today, travellers could use a navigation app of their choice to plan a trip, but with added functionality to schedule, pay and apply travel funds across mobility providers. For example, a traveller may pre-book or request an on-demand trip from a shared autonomous electric vehicle, get assigned a pick-up location for a flexible minibus, or reserve a shared electric bicycle at the rail station to make for a seamless transfer. Competition and bundling of services allows for greater mobility when needed.

address them while preparing for a world with autonomous vehicles. Solutions to address congestion, crashes and emissions must maximize benefits for as many people as possible. Regressive policies are to be avoided, and travel improvements should seek access to education, healthcare and jobs for all ${ }^{1,15}$.

The COVID-19 pandemic has illustrated how shifting the locations, start times and durations of activities can lessen congestion by spreading out peak demand. To manage urban growth and use scarce roadway capacity judiciously, shifting travel to off-peak periods may be part of the solution. Although tolling previously 'free' roads is a politically heated decision, cities have already or are beginning to develop (de)congestion pricing schemes (including London, Singapore and New York City $)^{16,17}$. Congestion pricing often uses dynamic tolls that rise and fall due to demand so that vehicles can travel closer to the designed speed, which might lock in the post-pandemic redistribution of traffic levels, and lower total vehicle-miles travelled and emissions ${ }^{18}$

Revenue-neutral, credit-based congestion pricing can address equity concerns that low-income, underserved households, who live further from jobs and may not have reliable and convenient public transit, are most financially burdened ${ }^{19,20}$. All adults receive a transportation credit (allocated from the tolling budget) to spend on local travel. Below-average motorists who take short and infrequent trips, ride public transit or travel during non-peak times can receive credits as compensation, while above-average, peak-period drivers pay out-of-pocket after depleting the credit. Credits may be redistributed to low-income households that have higher mobility needs due to the housing affordability crisis. However, changes in land-use policy, such as upzoning, are also necessary to create affordable, multi-modal communities that offer travellers viable alternatives under credit-based congestion pricing. This new policy rewards travellers that make small changes to reduce network congestion and has co-benefits of reducing emissions and crashes from stop-and-go traffic ${ }^{21}$.

While credit-based congestion pricing emphasizes reducing congestion, replacing the gas tax may help transportation financing issues. Gas taxes will become irrelevant as households purchase electric vehicles, and implementing a separate electric vehicle charging tax is unnecessary if GPS-based onboard devices can tally (de)congestion tolls and vehicle-milestravelled fees. Changes in vehicle efficiency previously impacted the volumetric-based gas tax, while the distance-based fee can finally shift responsibility for transportation funding to those driving the most. The fee structure, if designed as a flat rate, will hurt rural and low-income residents whose mobility needs are higher ${ }^{22}$. Tailoring vehicle-miles-travelled fees to the external cost of driving requires assigning costs based on driving location (urban versus rural), vehicle weight and vehicle carbon intensity. For example, larger vehicles wear out roads faster, increase crash severity and require more energy. Electric vehicles, which are generally heavier than combustion engine vehicles due to battery packs, may not pay higher fees because the carbon intensity of electricity in the United States is, for example, lower than gasoline. Urban regions are likely to benefit the most because they have higher external costs of driving (noise and air pollution, crashes and congestion, for instance). Rural regions will have lower per-mile fees to reflect lower external costs from pollution and congestion. Fatality rates, which are higher on rural roads, will lead to a higher share of per-mile fees coming from crash costs, which will help fund mitigation strategies.

Pricing guardrails for new technology Ride-hailing operators and transit agencies providing shared autonomous electric vehicle 
and minibus services will face the same vehicle-miles-travelled fees as individual motorists driving or riding in a personal autonomous vehicle. Shared autonomous electric vehicle operators competing for market share will weigh repositioning of vehicles against empty-travel fees. Cities should impose caps on shares of empty miles travelled (for mobility providers) while banning personal autonomous vehicles from travelling unoccupied on public roads. Personal autonomous vehicles may provide mobility benefits for families with young children and the elderly who cannot drive, but not at the expense of others. For example, cities will want to avoid hundreds of personal autonomous vehicles picking up curbside orders or driving around the city to find free parking.

With new pricing mechanisms (credit-based congestion pricing and vehicle-miles-travelled fees) and zero-occupancy caps/bans, the arrival of autonomous vehicles could look like the second self-driving future. Distance-based fees disincentivize sprawl and long-distance leisure trips that come with cheaper, easier travel via autonomous vehicle technology. Credit-based (de)congestion pricing will raise vehicle occupancies by incentivizing ridepooling and may nudge people to abandon personal car ownership in favour of shared vehicles. Travel credits from credit-based congestion pricing can be spent on any travel mode, including public transit or shared micromobility, such as electric bicycles. By addressing transportation challenges upfront via pricing, the advent of autonomous vehicles may avoid the 'potholes' of congestion, lane expansion and environmental harms.

Adequate funding for system maintenance and investment is needed and can be performed in conjunction with (de)congestion schemes to optimize the use of existing assets. Implementing progressive transportation financing now is necessary to define the market environment for emerging technologies, including electric vehicles and autonomous vehicles. However, pricing is just a part of the solution. Policymakers must combine transportation pricing reforms with land-use changes to provide access to opportunities for all and offer truly convenient, affordable and reliable travel choices.

\section{Matthew D. Dean (D) and Kara Kockelman ${ }^{\mathbb{1}}$ University of Texas at Austin, Austin, TX, USA. $凶_{\text {e-mail: kkockelm@mail.utexas.edu }}$}

Published online: 31 January 2022 https://doi.org/10.1038/s41928-021-00708-4

\section{References}

1. Litman, T. Autonomous Vehicle Implementation Predictions: Implications for Transport Planning (Victoria Transport Policy Institute, 17 December 2021); https://go.nature.com/3pmebCn

2. Fagnant, D. J. \& Kockelman, K. Transport. Res. Part A 77, 167-181 (2015).

3. Shared-Use Mobility Center Learning Module: Shared Autonomous Vehicles (MOD Learning Center, 2021); https://go.nature.com/30RRCvW
4. Bansal, P. \& Kockelman, K. M. Transport. Res. Part A 95 49-63 (2017).

5. Lavieri, P. S. et al. Transport. Res. Record 2665, 1-10 (2017).

6. Menon, N., Barbour, N., Zhang, Y., Pinjari, A. R. \& Mannering, F Int. J. Sustain. Transport. 13, 111-122 (2019).

7. Simoni, M. D. \& Kockelman, K. M. in International Encyclopedia of Transportation (ed. Vickerman, R.) 19-25 (Elsevier, 2021).

8. Wellik, T. \& Kockelman, K. J. Transport Land Use 13, 185-205 (2020).

9. The next pandemic surge: traffic. Transport Matters https:// go.nature.com/3eiu4nl (Institute for Transportation \& Development Policy, March 2021).

10. Perrine, K. A., Kockelman, K. M. \& Huang, Y. J. Transport Geography 82, 102547 (2020).

11. Lee, J. \& Kockelman, K. M. Energy and emissions implications of self-driving vehicles. In 98th Annual Meeting of the Transportation Research Board (2019).

12. Zipper, D. The dangerous promise of the self-driving car. Bloomberg CityLab https://go.nature.com/32j5IXS (October 2021).

13. Huang, Y., Kockelman, K. M., Garikapati, V., Zhu, L. \& Young, S. Transport. Res. Record 2675, 135-149 (2021).

14. Huang, Y., Kockelman, K. M. \& Truong, L. T. J. Adv. Transport. 2021, e5577500 (2021).

15. Fleming, K. L. J. Sci. Policy Governance 13, 20 (2018).

16. Gu, Z., Liu, Z., Cheng, Q. \& Saberi, M. Case Stud. Transport Policy 6, 94-101 (2018).

17. Decongestion fee system (Southern California Association of Governments, 2018); https://go.nature.com/3Ja2d6O

18. Parks, H. Investigating the impact of congestion pricing around the world. ClimateXChange https://go.nature.com/3egQPrw (29 May 2019).

19. Kalmanje, S. \& Kockelman, K. M. Transport. Res. Record 1864 , 45-53 (2004).

20. Li, W., Kockelman, K. M. \& Huang, Y. Transport. Res. Record 2675, 10-24 (2021).

21. Litman, T. Pricing for Traffic Safety: How Efficient Transport Pricing Can Reduce Roadway Crash Risks https://go.nature. com/3H4tR31 (Victoria Transport Policy Institute, 22 April 2021)

22. Larsen, L., Burris, M., Pearson, D. \& Ellis, P. Transport. Res. Record 2297, 11-20 (2012).

Competing interests

The authors declare no competing interests. 